\title{
Noradrenalin effectively rescues mice from blast lung injury caused by laser-induced shock waves
}

\author{
Hiroki Miyawaki ${ }^{1}$, Daizoh Saitoh ${ }^{2 *}$, Kohsuke Hagisawa ${ }^{3}$, Midori Noguchi ${ }^{2}$, Shunichi Sato ${ }^{4}$, Manabu Kinoshita $^{5}$,
} Hiromi Miyazaki ${ }^{2}$, Yasushi Satoh ${ }^{6}$, Nahoko Harada ${ }^{7}$ and Toshihisa Sakamoto ${ }^{1}$

\author{
* Correspondence: \\ ds0711@ndmc.ac.jp \\ ${ }^{2}$ Division of Traumatology, Research \\ Institute, National Defense Medical \\ College, 3-2 Namiki, Tokorozawa \\ 359-8513, Japan \\ Full list of author information is \\ available at the end of the article
}

\begin{abstract}
Background: Blast lung injuries (BLI) caused by blast waves are extremely critical in the prehospital setting, and hypotension is thought to be the main cause of death in such cases. The present study aimed to elucidate the pathophysiology of severe BLI using laser-induced shock wave (LISW) and identify the initial treatment.

Methods: The current investigation comprised two parts. For the validation study, mice were randomly allocated to groups that received a single shot of 1.2, 1.3, or $1.4 \mathrm{~J} / \mathrm{cm}^{2}$ LISW to both lungs. The survival rates, systolic blood pressure (sBP), heart rate $(\mathrm{HR})$, peripheral oxyhemoglobin saturation $\left(\mathrm{SpO}_{2}\right)$, and shock index were monitored for $60 \mathrm{~min}$, and lung tissues were analyzed histopathologically. The study evaluated the effects of catecholamines as follows. Randomly assigned mice received $1.4 \mathrm{~J} / \mathrm{cm}^{2}$ LISW followed by the immediate intraperitoneal administration of dobutamine, noradrenalin, or normal saline. The primary outcome was the survival rate. Additionally, sBP, $\mathrm{HR}, \mathrm{SpO}_{2}$, and the shock index were measured before and 5 and 10 min after LISW, and the cardiac output, left ventricular ejection fraction, and systemic vascular resistance (SVR) were determined before and 1 min after LISW.
\end{abstract}

Results: The triad of BLI (hypotension, bradycardia, and hypoxemia) was evident immediately after LISW. The survival rates worsened with increasing doses of LISW (100 \% in $1.2 \mathrm{~J} / \mathrm{cm}^{2}$ vs. $60 \%$ in $1.3 \mathrm{~J} / \mathrm{cm}^{2}, 10 \%$ in $\left.1.4 \mathrm{~J} / \mathrm{cm}^{2}\right)$. The histopathological findings were compatible with those of human BLI. The survival rate in LISW high group $\left(1.4 \mathrm{~J} / \mathrm{cm}^{2}\right)$ was highest in the group that received noradrenalin (100\%), with significantly elevated SVR values (from 565 to 1451 dyn s/min ${ }^{5}$ ). In contrast, the survival rates in the dobutamine and normal saline groups were 40 and $10 \%$, respectively, and the SVR values did not change significantly after LISW in either group.

Conclusions: The main cause of death during the initial phase of severe BLI is hypotension due to the absence of peripheral vasoconstriction. Therefore, the immediate administration of noradrenalin may be an effective treatment during the initial phase of severe BLI.

Keywords: Blast lung injury, Initial phase, Laser-induced shock wave, Noradrenalin, Peripheral vasoconstriction

\section{Springer}

๑) 2015 Miyawaki et al. Open Access This article is distributed under the terms of the Creative Commons Attribution 4.0 International License (http://creativecommons.org/licenses/by/4.0/), which permits unrestricted use, distribution, and reproduction in any medium, provided you give appropriate credit to the original author(s) and the source, provide a link to the Creative Commons license, and indicate if changes were made. 


\section{Background}

Blast waves caused by explosions can cause death, even in the absence of external injuries $[1,2]$. Physicians should be aware that blast injuries are not only an important cause of trauma in military conflicts, but also during acts of terrorism in civil settings. The physical damage inflicted by blast waves is called primary blast injury, which has become more prevalent because of recent changes in the characteristics of warfare and terrorism [3-6].

When blast waves pass from a solid into a gas-filled tissue interface, compressive stress is converted into a tension wave. Therefore, gas-filled organs, such as the lungs, gastrointestinal tract, and auditory system, are vulnerable to blast waves $[2,3,6,7]$, among which, blast injuries to the lungs can be the most lethal during the initial phase [7-12]. The severity of blast lung injuries (BLI) usually determines subsequent mortality [2].

Primary blast injury to the thorax produces the triad of BLI, namely, bradycardia $[4,11,13]$, prolonged hypotension $[4,11,13]$, and hypoxemia $[8,14]$. Hypotension and hypoxemia due to BLI are the most serious life-threatening complications of primary blast injuries in initial survivors $[5,13]$. However, rigorous efforts directed toward elucidating the etiology of hypotension have not yielded much information. Hence, treatment for severe BLI during the initial phase remains insufficient. There are currently arguments that hypotension might be mediated by the absence of vasoconstriction $[13,15,16]$ and/or decreased cardiac output [16, 17]. Irwin et al. reported that blast-induced circulatory shock results from immediate myocardial depression without compensatory vasoconstriction [16]. However, none of these studies identified the effects of catecholamines, which are believed to increase vascular resistance and/or cardiac output.

Conventional models of blast injuries require the use of real explosives and complex shock tubes or blast generators to create shock waves. Such methods are rather costly and associated with physical hazards, which might have prevented the advancement of effective treatments for BLI. However, Satoh et al. recently introduced a novel laboratory-based small-animal model using laser-induced shock wave (LISW) [18, 19]. The LISW method is highly controllable and reproducible and can be implemented in simple experimental settings.

We hypothesized that the main cause of immediate death in individuals with severe BLI is hypotension due to an absence of peripheral vasoconstriction and that the immediate administration of an $\alpha 1$-adrenergic receptor agonist directly after exposure to blast waves may improve the acute prognosis. We thus examined the effects of catecholamines during the initial phase of severe BLI elicited by a high-dose LISW.

\section{Methods}

Animals

Inbred male 8- to 10-week-old C57BL/6 mice were housed under specific pathogenfree conditions in an environmentally controlled clean room under a 12-h light/dark schedule. All experiments proceeded according to the institutional ethical guidelines for animal experiments of the National Defense Medical College, and the Committee for Animal Research at the National Defense Medical College (Tokorozawa, Saitama, 
Japan) approved the study (permission number: 11045). The animals were planned to be sacrificed via $5 \%$ sevoflurane administration followed by cervical dislocation when they demonstrated pain caused by their behaviors (struggling or screaming).

\section{Shock wave generator}

Briefly, LISW were generated by irradiating a laser target with a 694-nm Q-switched ruby laser (NIIC Co., Ltd., Tokyo, Japan) at a pulse width of $20 \mathrm{~ns}$ at full-width halfmaximum (FWHM). The laser target was a 20 -mm-diameter, 0.5 -mm-thick black natural rubber disk, upon which a 1.0-mm-thick transparent polyethylene terephthalate sheet was bonded to confine the laser-induced plasma to increase the LISW impulse. The laser spot on the target was elliptical, and the longer and shorter axes were $\sim 11$ and $\sim 9 \mathrm{~mm}$, respectively (Fig. 1).

\section{Instrumentation and physiological measurements}

The dorsal chest and neck regions of the mice were treated with a topical depilatory agent to avoid air becoming trapped in the fur and in preparation for the placement of the sensor over the carotid region. The ventral chest region was similarly prepared for echocardiography.

The mice continuously inhaled $1.5 \%$ sevoflurane in air via a nose cone for anesthesia.

The peripheral oxyhemoglobin saturation $\left(\mathrm{SpO}_{2}\right)$ and heart rate $(\mathrm{HR})$ were measured using a MouseOX veterinary pulse oximeter (STARR Life Sciences Corp., Oakmont, PA, USA). Systolic blood pressure (sBP) was assessed using the MK-2000ST nonpreheating, non-invasive blood pressure monitor system for mice and rats (Muromachi, Tokyo, Japan) while the mice were fixed on a plate in the prone position. The shock index was estimated using the equation: HR / sBP.

Cardiac output (CO) and the left ventricular ejection fraction (EF) were measured using an ellipsoid single-plane algorithm using a Vevo 770 high-resolution imaging system (Fujifilm VisualSonics Inc., Toronto, Canada) at $40 \mathrm{MHz}$ with a frame rate of $30 \mathrm{~Hz}$ while the mice were fixed on a plate in the supine position. Systemic vascular resistance (SVR) was estimated using the equation: $80 \times 1000 \times($ mean arterial pressure) / (stroke volume $\times \mathrm{HR}$ ) dyn $\mathrm{s} / \mathrm{cm}^{5}$, where HR represents the heart rate.

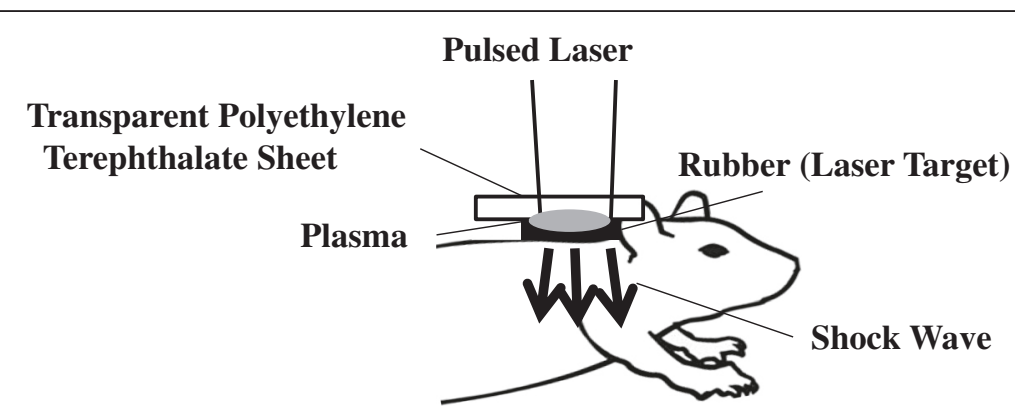

Fig. 1 Experimental protocol for the mouse model of pulmonary blast injury using laser-induced shock wave (LISW) treatment. Black rubber laser target with a Q-switched ruby laser was irradiated to generate LISW. Plasma formed at the interface between the transparent material and black rubber. Patches were placed on the dorsal skin over the right and left lungs to generate bilateral lung damage 


\section{Experimental protocol}

The mice were left to equilibrate for $15 \mathrm{~min}$ before baseline values for $\mathrm{HR}, \mathrm{sBP}, \mathrm{SpO}_{2}$, shock index, EF, CO, and SVR were determined.

Most areas of the bilateral lungs were exposed to single LISW each (except for the Sham group). Ultrasound conductive gel placed between the laser target and skin surface ensured acoustic impedance matching.

\section{Validation of BLI induced by LISW}

The mice were randomly allocated to receive 1.2 (LISW low group; $n=10$ ), 1.3 (LISW medium group; $n=16$ ), or 1.4 (LISW high group; $n=10) \mathrm{J} / \mathrm{cm}^{2}$ of LISW or no waves (Sham group; $n=7$ ). The baseline sBP, $\mathrm{HR}, \mathrm{SpO}_{2}$, and shock index values were measured before exposure to LISW. After delivering LISW twice at each dose, the survival rate, $\mathrm{sBP}, \mathrm{HR}, \mathrm{SpO}_{2}$, and shock index were measured every $5 \mathrm{~min}$ for $1 \mathrm{~h}$. The mice were not intubated or ventilated in order to mimic clinically relevant chest trauma conditions.

Death was defined as the absence of an sBP measurement with no movements of any part of the body for $>15 \mathrm{~min}$.

\section{Histopathological characteristics}

The mice were euthanized $1 \mathrm{~h}$ after LISW, and then isolated tracheas were cannulated with 22-gauge catheters. The lungs were inflated, fixed with $4 \%$ paraformaldehyde at $10 \mathrm{~cm} \mathrm{H}_{2} \mathrm{O}$ pressure, dehydrated, and sliced into sections for staining with hematoxylin-eosin. All experiments comprised at least four mice.

\section{Effects of noradrelalin and dobutamine on survival rates and physiological parameters}

The baseline sBP, HR, $\mathrm{SpO}_{2}$, and shock index values were measured before LISW delivery, after which the mice were randomly allocated to the Sham group $(n=5)$, which received no LISW or drugs, a group that received $60 \mu \mathrm{g}$ of dobutamine in $0.1 \mathrm{~mL}$ of saline (DOB group; $n=10$ ), a group that received $20 \mu \mathrm{g}$ of noradrenalin in $0.1 \mathrm{~mL}$ of saline (NA group; $n=10$ ), or a group that received $0.1 \mathrm{~mL}$ of normal saline alone (NS group; $n=10$ ) via intraperitoneal bolus injection immediately after delivering $1.4 \mathrm{~J} / \mathrm{cm}^{2}$ LISW twice.

The sBP, $\mathrm{HR}, \mathrm{SpO}_{2}$, and shock index were measured at 5 and $10 \mathrm{~min}$ after LISW in the dobutamine (DOB), noradrenalin (NA), and normal saline (NS) groups. The survival rates were calculated every $5 \mathrm{~min}$ for $1 \mathrm{~h}$ after LISW.

\section{Effects on hemodynamic parameters}

The baseline sBP and HR values were measured before LISW. CO, EF, and SVR were calculated from the left ventricular end-diastolic and end-systolic volumes obtained using the ellipsoid single-plane algorithm. The mice received $1.4 \mathrm{~J} / \mathrm{cm}^{2}$ LISW twice as described above and were then randomly allocated to the following groups: $60 \mu \mathrm{g}$ of dobutamine in $0.1 \mathrm{~mL}$ of saline (DOB group; $n=5$ ), $20 \mu \mathrm{g}$ of noradrenalin in $0.1 \mathrm{~mL}$ of saline (NA group; $n=5$ ), or $0.1 \mathrm{~mL}$ of normal saline alone (NS group; $n=5$ ) via intraperitoneal bolus injection immediately after LISW. 


\section{Statistical analysis}

The baseline values for sBP, HR, shock index, and $\mathrm{SpO}_{2}$ obtained before LISW were assessed using a one-factor ANOVA. The baseline values of CO, EF, and SVR were assessed using the Kruskal-Wallis test. The survival periods were compared among the groups using the Kaplan-Meier method with the log-rank test. Changes in the sBP, HR, $\mathrm{EF}$, and SVR values were assessed using a repeated measures ANOVA, paired $t$ test, or Wilcoxon signed-rank test. The values are shown as the mean \pm standard error. A $p$ value of $<0.05$ was considered to be significant.

\section{Results}

\section{Validation of BLI induced by LISW}

As shown in Table 1, the baseline sBP, $\mathrm{HR}, \mathrm{SpO}_{2}$, and shock index values did not differ significantly among the four groups.

Figure 2 shows that the survival rates of each group at $1 \mathrm{~h}$ after LISW significantly decreased as the dose of LISW increased, and lethality was most evident within $15 \mathrm{~min}$ after LISW in mid-intensity $\left(1.3 \mathrm{~J} / \mathrm{cm}^{2}\right)$ and high-intensity $(1.4 \mathrm{~J} /$ $\mathrm{cm}^{2}$ ) groups, whereas none of the mice died after $15 \mathrm{~min}$.

As shown in Fig. $3 \mathrm{a}-\mathrm{c}, \mathrm{sBP}, \mathrm{HR}$, and $\mathrm{SpO}_{2}$ rapidly decreased soon after exposure to LISW. Low-intensity $\left(1.2 \mathrm{~J} / \mathrm{cm}^{2}\right)$ LISW led transient shock at $5 \mathrm{~min}$ later LISW, when the shock index increased 1.5 times as that noted at baseline. Then, the sBP dropped to less than $60 \mathrm{mmHg}$ and thereafter gradually increased again to more than $60 \mathrm{mmHg}$, while the shock index returned to the baseline level. In addition, LISW clearly decreased sBP, and it remained decrease for at least $1 \mathrm{~h}$ in LISW low group in Fig. 3a. $\mathrm{SpO}_{2}$ also remained decrease for at least $1 \mathrm{~h}$ in Fig. 3b.

Mid-intensity $\left(1.3 \mathrm{~J} / \mathrm{cm}^{2}\right)$ LISW prolonged shock $(\mathrm{sBP}<50 \mathrm{mmHg}$ and shock index 1.5 times) beyond $10 \mathrm{~min}$ after LISW, and six of 16 mice died within $15 \mathrm{~min}$.

High-intensity $\left(1.4 \mathrm{~J} / \mathrm{cm}^{2}\right)$ LISW significantly attenuated the HR. Hence, the shock index decreased in a pseudonormal pattern and the sBP decreased to approximately $40 \mathrm{mmHg}$. Therefore, nine of the ten mice might have died because of sustained shock.

\section{Histopathological characteristics}

Diffuse hemorrhage occurred in both lungs. An evaluation of lung samples using microscopy revealed endobronchial hemorrhage and diffuse alveolar over-distension (Fig. 4). In contrast, a few sites of perivascular (cuff-like) hemorrhage were evident (Fig. 4).

Table 1 Baseline physiological data recorded before LISW

\begin{tabular}{llllll}
\hline & Sham & $\begin{array}{l}1.2 \mathrm{~J} / \mathrm{cm}^{2} \text { (LISW } \\
\text { low group) }\end{array}$ & $\begin{array}{l}1.3 \mathrm{~J} / \mathrm{cm}^{2} \text { (LISW } \\
\text { medium group) }\end{array}$ & $\begin{array}{l}1.4 \mathrm{~J} / \mathrm{cm}^{2} \text { (LISW } \\
\text { high group) }\end{array}$ & $p$ value \\
\hline$n$ & 7 & 10 & 16 & 10 & \\
$\mathrm{HR}$ (beats/min) & $530 \pm 16.1$ & $548 \pm 13.5$ & $531 \pm 12.1$ & $533 \pm 14.7$ & 0.801 \\
$\mathrm{sBP}(\mathrm{mmHg})$ & $83.9 \pm 4.3$ & $89.2 \pm 4.5$ & $84.2 \pm 3.1$ & $79.5 \pm 4.1$ & 0.428 \\
$\mathrm{SpO}_{2}(\%)$ & $98.1 \pm 0.6$ & $98.3 \pm 0.3$ & $97.2 \pm 0.5$ & $97.2 \pm 0.6$ & 0.396 \\
Shock index & $6.06 \pm 1.6$ & $6.32 \pm 0.4$ & $6.42 \pm 0.2$ & $6.91 \pm 0.5$ & 0.451 \\
\hline
\end{tabular}

$n$ number of mice, $H R$ heart rate, $s B P$ systolic blood pressure, $\mathrm{SpO}_{2}$ peripheral oxyhemoglobin saturation, n.s. not significant (one-factor ANOVA). Data are presented as the mean \pm standard error 


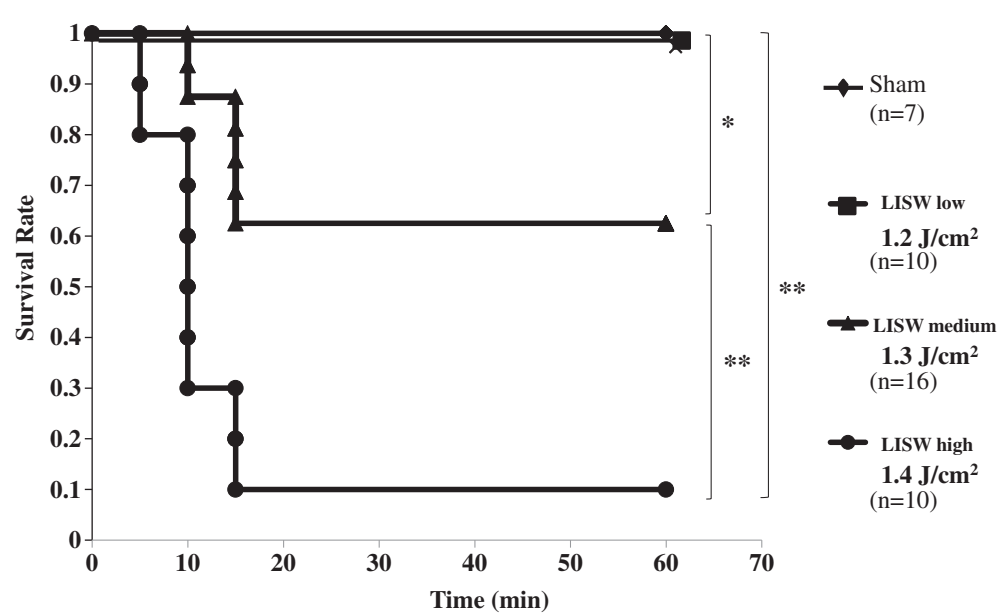

Fig. 2 Kaplan-Meier survival curves for the mice exposed to 1.2, 1.3, and $1.4 \mathrm{~J} / \mathrm{cm}^{2}$ of LISW. Data were recorded every $5 \mathrm{~min}$ for $60 \mathrm{~min}$ after the mice were exposed twice to 1.2 (LISW low group), 1.3 (LISW medium group), or 1.4 (LISW high group) $\mathrm{J} / \mathrm{cm}^{2}$. Sham mice were not exposed to LISW. ${ }^{*} p<0.01 ;{ }^{*} p<0.05$ (log-rank test)

Effects of noradrenalin and dobutamine on survival rates and physiological parameters

The baseline sBP, $\mathrm{HR}, \mathrm{SpO}_{2}$, and shock index values were at the same levels in the dobutamine (DOB), noradrenalin (NA), and normal saline (NS) groups (Table 2). The survival rates in both catecholamine groups were significantly higher than that seen in the NS group after exposure to $1.4 \mathrm{~J} / \mathrm{cm}^{2}$ of LISW (Fig. 5). All Sham animals survived until the end of the study. Nine $(90 \%)$ of the NS group mice died within 15 min after LISW. Four (0 \%) mice in the DOB group survived until the end of the study. One (10\%) mouse died after $45 \mathrm{~min}$, and five (50\%) mice died within $15 \mathrm{~min}$. All mice in the NA group survived until the end of the observation. The survival rates were significantly higher in the NA and DOB groups than in the NS group $(p<0.01$ and $p<0.05$, respectively) and in the NA group than in the DOB group $(p<0.01)$.

For the analysis of physiological parameters, the mice for which we could not obtain both SBP and HR values were excluded (five mice were excluded in each group) because we could not measure sBP, $\mathrm{HR}$, or $\mathrm{SpO}_{2}$ in five mice of the NS or DOB group due to peripheral circulatory failure. Moreover, we failed to measure sBP and HR using a non-invasive blood pressure monitor system in five mice of the NA group. HR significantly decreased in all groups after 5 and $10 \mathrm{~min}$ of LISW, although NA and DOB mitigated bradycardia in comparison with that observed in the NS group ( $p<0.01$ and $p<0.05$, respectively) (Fig. 6a). NA administration maintained the sBP values above $70 \mathrm{mmHg}$ (Fig. $6 \mathrm{~b}$ ) and resulted in the same shock index (Fig. 6d), even after LISW, while the sBP values were not more than $55 \mathrm{mmHg}$ in the other groups (Fig. 6b). As a result, DOB did not maintain the hemodynamics, and the shock index increased 1.5 times the baseline level (Fig. 6d). As for the NS group, severe bradycardia occurred, as in validation study (Fig. 6a), and the shock index decreased in a pseudonormal pattern (Fig. 6d).

The $\mathrm{SpO}_{2}$ at 5 min similarly and significantly decreased after LISW in all three groups and did not change for up to $10 \mathrm{~min}$ thereafter (Fig. 6c). 


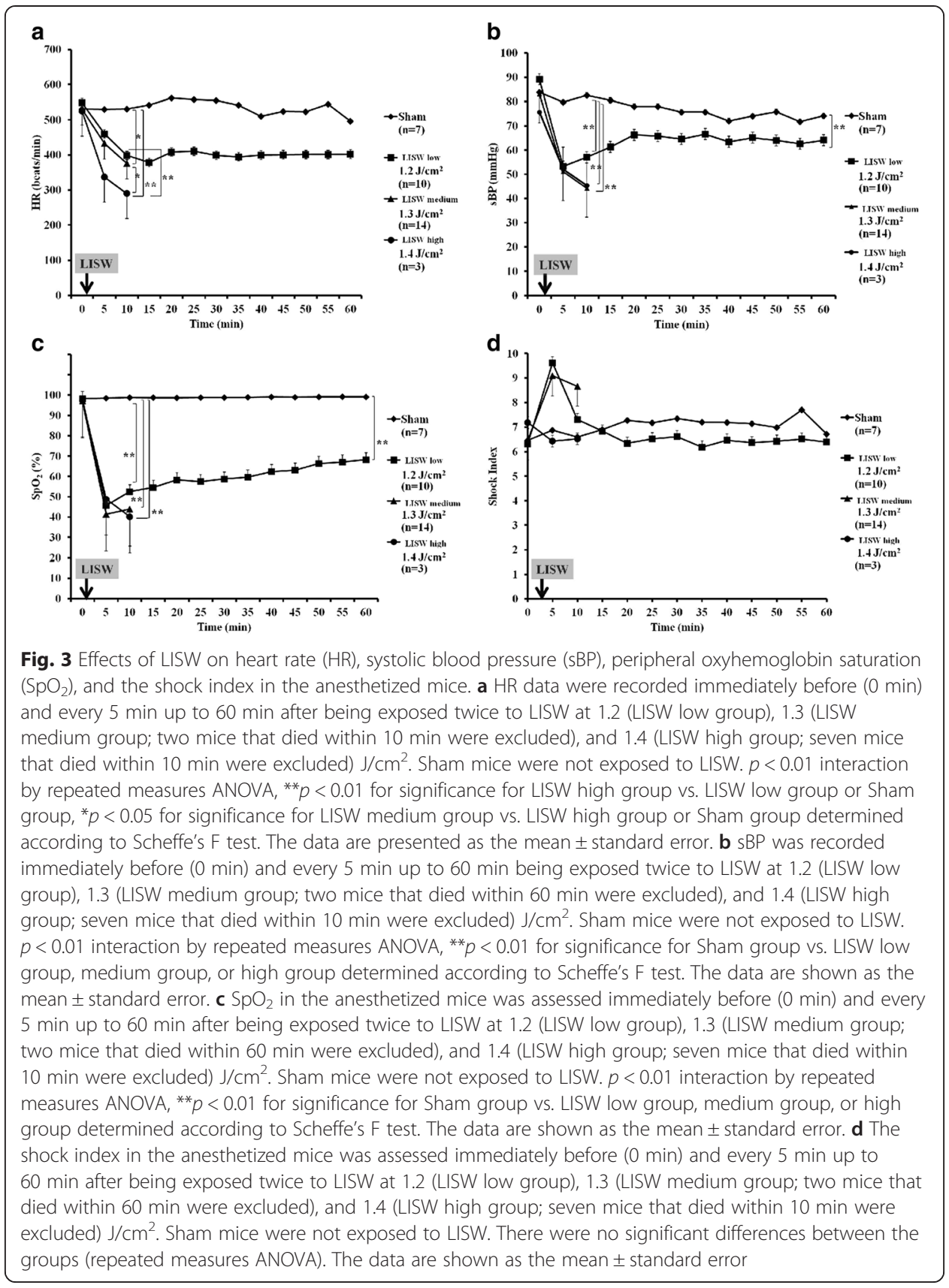

\section{Effect on hemodynamic parameters}

The baseline EF, CO, and SVR values did not differ significantly among the groups (Table 3). EF and CO modestly decreased in the DOB group after LISW (68 to $66 \%$, 11.1 to $7.8 \mathrm{ml} / \mathrm{min}$ ), whereas both significantly decreased in the NA and NS groups (74 to $51 \%, 12.3$ to $4.1 \mathrm{ml} / \mathrm{min}, 69$ to $45 \%, 9.9$ to $4.3 \mathrm{ml} / \mathrm{min}$ ) (Fig. $7 \mathrm{a}, \mathrm{b}$ ). DOB preserved $\mathrm{CO}$ and $\mathrm{EF}$, as DOB stimulated cardiac contractility. NA administration significantly increased SVR 2.6-fold the baseline level, even after LISW exposure (565 to 1451 dyn s/ $\min ^{5}, p<0.05$ ) (Fig. 7c), whereas the SVR values remained unchanged in the DOB and NS groups (796 to 699, 747 to $983 \mathrm{dyn} \mathrm{s} / \mathrm{min}^{5}$, respectively) (Fig. 7c). 


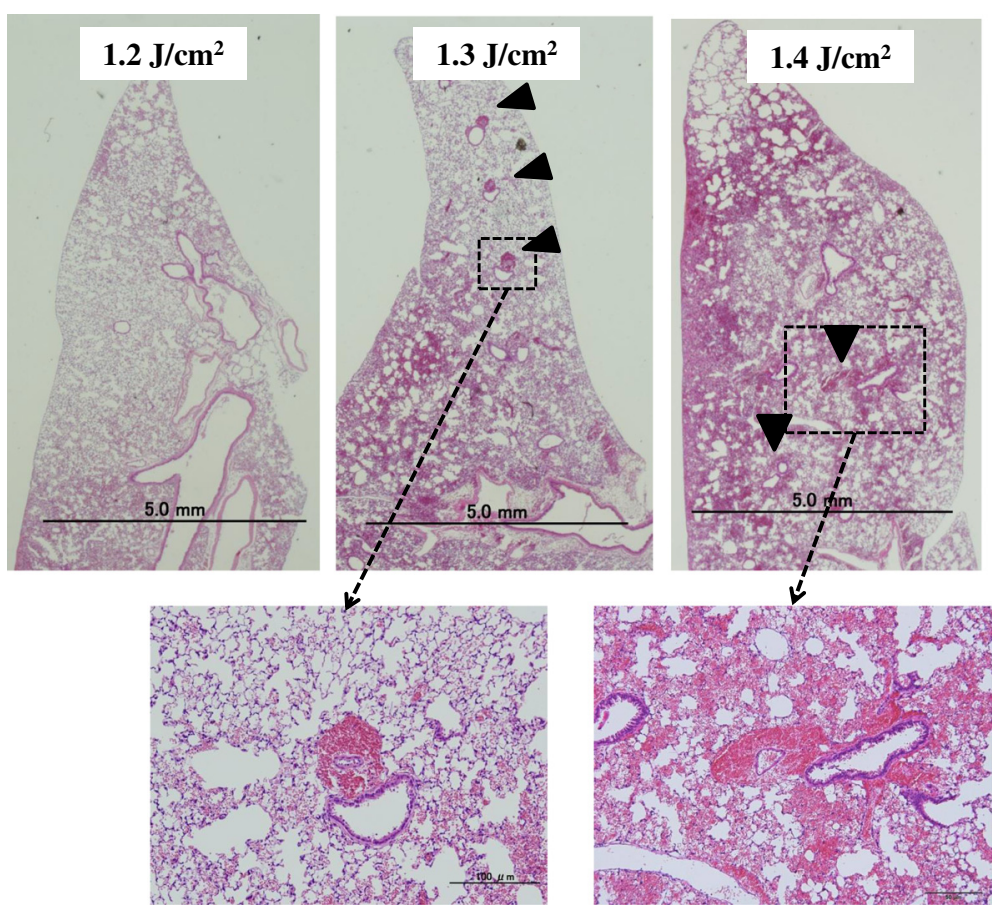

Fig. 4 Representative sections of mouse lungs histologically stained with hematoxylin and eosin after exposure to $1.2,1.3$, and $1.4 \mathrm{~J} / \mathrm{cm}^{2}$ of LISW. In each group, intra-alveolar and endobronchial hemorrhage and diffuse alveolar over-distension were evident. Perivascular cuff-like hemorrhage (arrowheads) were seen sporadically

\section{Discussion}

Although the rate of primary blast injury (damage caused by blast waves) has historically been lower than that of secondary blast injury (damage caused by projectiles propelled by blast wind), this rate is currently approaching that of secondary blast injury. Studies published before the twenty-first century show rates of primary blast injury between 0.9 and $8.4 \%[20,21]$, whereas recent reports indicate rates between 14 and $86 \%[1,2,4,20]$. One explanation for why the clinical importance of BLI in warfare has been increasing is the increased prevalence of personal body armor for soldiers capable of protecting against secondary, but not primary, blast injuries [6, 7, 22]. In civilian settings, terrorists tend to set bombs in confined spaces, such as trains, busses or buildings in order to magnify the duration and range of blast waves by forcing energy to rebound off surfaces $[1,5-7,9,20,23]$.

Most deaths due to BLI occur immediately after blast exposure during the initial phase (prehospital setting) [7-10, 20, 24]. Although no documents have clearly defined the duration immediately after injury, it is generally considered that $15-30 \mathrm{~min}$ is necessary to evacuate the patient to the hospital. In the present study, we defined the initial phase as within 30 min after injury, which is in agreement with the fact that most of the mice died within 15 min after LISW in this study. Our model therefore seems to be compatible with the characteristics of severe BLI. In addition, BLI is clinically characterized by the triad of bradycardia, hypotension, and hypoxemia. We also found this triad in validation study.

The micromorphological equivalents of BLI can be summarized as including diffuse alveolar over-distension, alveolar and endobronchial hemorrhage, circumscribed interstitial 
Table 2 Baseline physiological data recorded before LISW

\begin{tabular}{llllll}
\hline & Sham & $\begin{array}{l}\text { Normal saline } \\
\text { (NS group) }\end{array}$ & $\begin{array}{l}\text { Noradrenalin } \\
\text { (NA group) }\end{array}$ & $\begin{array}{l}\text { Dobutamine } \\
\text { (DOB group) }\end{array}$ & $p$ value \\
\hline$n$ & 5 & 10 & 10 & 10 & \\
$\mathrm{HR}($ beats $/ \mathrm{min})$ & $530 \pm 16.1$ & $525.8 \pm 20.1$ & $515 \pm 21.8$ & $414 \pm 29.8$ & 0.941 \\
$\mathrm{sBP}(\mathrm{mmHg})$ & $83.9 \pm 4.3$ & $83.4 \pm 3.4$ & $79.8 \pm 4.8$ & $95 \pm 4.6$ & 0.069 \\
$\mathrm{SpO}_{2}(\%)$ & $98.1 \pm 0.6$ & $98.3 \pm 0.3$ & $97.2 \pm 0.5$ & $97.2 \pm 0.6$ & 0.282 \\
Shock index & $6.06 \pm 1.6$ & $6.32 \pm 0.4$ & $6.54 \pm 0.48$ & $5.52 \pm 0.24$ & 0.193 \\
\hline
\end{tabular}

$n$ number of mice, $H R$ heart rate, $s B P$ systolic blood pressure, $\mathrm{SpO}_{2}$ peripheral oxyhemoglobin saturation, $n$.s. not significant (one-factor ANOVA). Data are presented as the mean \pm standard error

hemorrhage with a cuff-like pattern around pulmonary vessels, venous air embolism, and pulmonary fat embolism [25]. We found diffuse alveolar over-distension and intraalveolar, endobronchial, and perivascular (cuff-like) hemorrhage in this model.

The etiology of the hypotension seen after BLI is complex. Previous studies suggest that it is due to the absence of peripheral vasoconstriction $[13,15,16]$ caused by inhibition of the sympathetic vasoconstrictor tone $[26,27]$ or release of potent vasodilator nitric oxide $[28,29]$. However, few studies have documented the details of the hemodynamic response, especially regarding cardiac contractions and SVR, to catecholamine administration after blast lung injury.

Indeed, we found that the SVR values did not change before and after LISW exposure despite severe hypotension in the NS and DOB groups. We evaluated the effects of noradrenaline, an $\alpha 1$-adrenergic receptor agonist that increases vascular resistance and a $\beta 1$-adrenergic receptor agonist that preserves $\mathrm{CO}$, and dobutamine, a $\beta 1$-adrenergic receptor agonist, during the initial phase of severe BLI. No compensatory increases in SVR occurred after LISW exposure in the NS group, and very low cardiac output caused hypotension. Although DOB preserved $\mathrm{CO}$ and EF, it did not prevent hypotension, as DOB stimulated cardiac contractility via the $\beta 1$-adrenergic receptor, although it did not affect peripheral vasoconstriction, as shown by the unchanged SVR

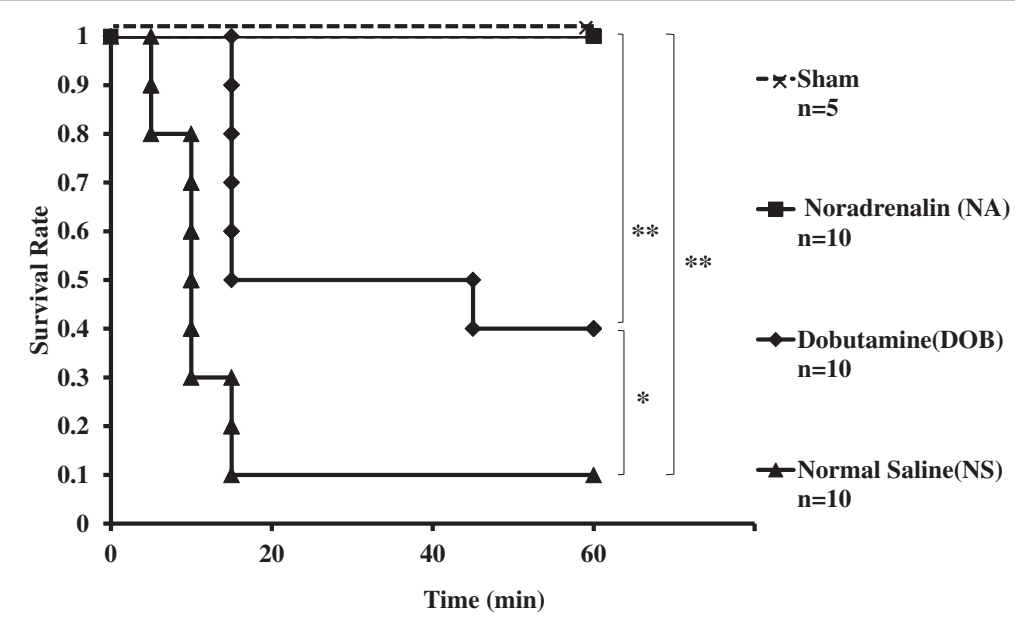

Fig. 5 Kaplan-Meier survival curves for the mice exposed twice to $1.4 \mathrm{~J} / \mathrm{cm}^{2}$ LISW and then administered a single intraperitoneal bolus of each drug. Data were recorded every $5 \mathrm{~min}$ for $60 \mathrm{~min}$. Sham mice were not exposed to LISW and instead administered $0.1 \mathrm{~mL}$ normal saline. NA, DOB, and NS groups were exposed twice to LISW and then received $20 \mu \mathrm{g}$ of noradrenaline, $60 \mu \mathrm{g}$ of dobutamine, and $0.1 \mathrm{~mL}$ of normal saline, respectively. ${ }^{* *} p<0.01 ;{ }^{*} p<0.05$ log-rank test 

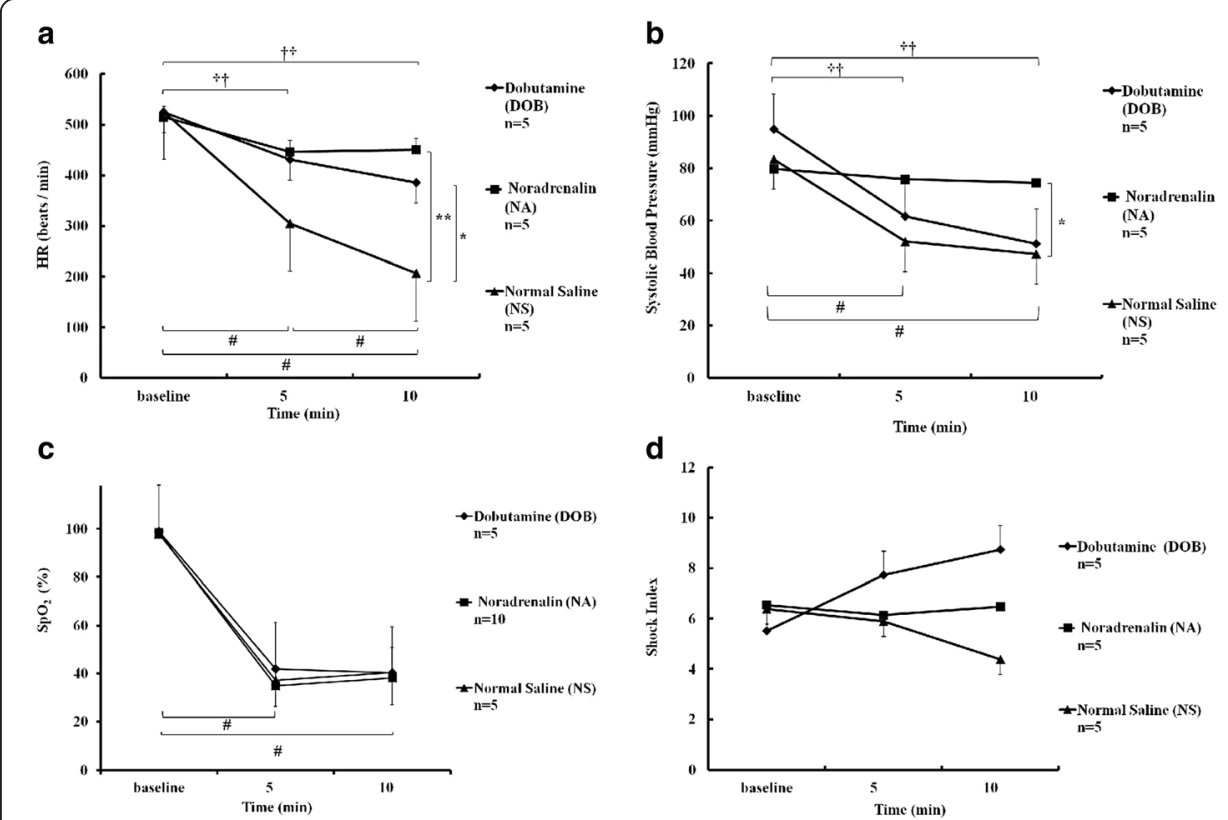

Fig. 6 Effect of the drugs administered to the mice immediately after being exposed twice to LISW at 1.4 $\mathrm{J} / \mathrm{cm}^{2}$ on systolic blood pressure (sBP), heart rate (HR), peripheral oxyhemoglobin saturation $\left(\mathrm{SpO}_{2}\right)$, and the shock index. a HR was measured immediately before (baseline) and at 5 and 10 min after LISW. NA, DOB, and NS groups were exposed twice to LISW and then received $20 \mu \mathrm{g}$ of noradrenaline, $60 \mu \mathrm{g}$ of dobutamine, and $0.1 \mathrm{~mL}$ of normal saline, respectively. $p<0.01$ interaction by repeated measures ANOVA, ${ }^{*} p<0.01 ;{ }^{*} p<0.05$ for significance between two groups determined according to Scheffe's F test. \#p< 0.05 ; significance between each value in NS group, baseline, and 5 min in NA group, and corresponding vs. 10 min-value in DOB group (Wilcoxon signed-rank test). $++p<0.01$; significance between baseline and 10 min in NA group, baseline, and 5 min in DOB group (paired $t$ test). The data are shown as the mean \pm standard error. b SBP was measured before (baseline) and at 5 and 10 min after LISW. NA, DOB, and NS groups were exposed twice to LISW and then received $20 \mu \mathrm{g}$ of noradrenaline, $60 \mu \mathrm{g}$ of dobutamine, and $0.1 \mathrm{~mL}$ of normal saline, respectively. $p<0.05$ interaction by repeated measures ANOVA, ${ }^{*} p<0.05$ for significance between two groups determined according to Scheffe's $F$ test. \#p $<0.05$; significance corresponding vs. baseline values in NS group (Wilcoxon signed-rank test). $+\uparrow p<0.01$; significance corresponding vs. baseline value in $\mathrm{DOB}$ group (paired $t$ test). c SpO 2 was measured immediately before (baseline) and at 5 and 10 min after LISW. \#p $<0.01$ vs. corresponding baseline values in all groups (paired $t$ test). $\mathbf{d}$ The shock index was measured immediately at baseline and 5 and $10 \mathrm{~min}$ after LISW. There were no significant differences between the groups or based on time

values. In contrast, NA increased SVR, stimulating peripheral vasoconstriction via the $\alpha 1$-adrenergic receptor, which consequently maintained sBP. Therefore, hypotension due to a lack of compensating vasoconstriction is the essential pathophysiology and therapeutic target of BLI. In addition, NA is also a $\beta 1$-adrenergic receptor agonist, but we think that the $\alpha 1$-adrenergic effect is a major factor affecting survival and BP maintenance immediately after LISW exposure because dobutamine, a $\beta 1$-adrenergic receptor agonist, could not maintain sBP in our model.

The survival rate was significantly higher in the noradrenaline group than in the dobutamine group, indicating that hypotension is the main cause of death due to BLI during the initial phase. The lack of peripheral vasoconstriction, rather than decreased $\mathrm{CO}$, is the main cause of the hypotension associated with BLI. Compensatory vasoconstriction adjusts the blood distribution from peripheral vessels toward central vital organs, such as the brain and heart. NA administration rationally allows for the blood to be distributed throughout the central vital organs, 
Table 3 Baseline cardiac data recorded before LISW

\begin{tabular}{lllll}
\hline & $\begin{array}{l}\text { Normal saline } \\
\text { (NS group) }\end{array}$ & $\begin{array}{l}\text { Noradrenalin } \\
\text { (NA group) }\end{array}$ & $\begin{array}{l}\text { Dobutamine } \\
\text { (DOB group) }\end{array}$ & $p$ value \\
\hline$n$ & 5 & 5 & 5 & \\
CO & $9.9 \pm 1.2$ & $12.3 \pm 1.0$ & $11.1 \pm 2.9$ & 0.688 \\
EF & $69.4 \pm 2.3$ & $74 \pm 2.2$ & $68.4 \pm 2.2$ & 0.276 \\
SVR & $747 \pm 72$ & $565 \pm 30$ & $796 \pm 158$ & 0.166 \\
\hline
\end{tabular}

$n$ number of mice, CO cardiac output, EF left ventricular ejection fraction, SVR systemic vascular resistance, n.s., not significant (Kruskal-Wallis test). Data are presented as the mean \pm standard error

subsequently preventing low cardiac output associated with severe bradycardia. However, DOB administration simultaneously increases $\mathrm{O}_{2}$ demand because of the positive inotropic effect, which fails to improve the acute survival rates. Therefore, NA, not DOB, acts as an effective treatment for the initial phase of severe BLI.

In addition, LISW clearly decreases sBP, and it remains decreased for at least $1 \mathrm{~h}$ in the LISW low group. We do not know the mechanism, but lung damage based on LISW exposure may influence the cardiac function because $\mathrm{SpO}_{2}$ also remains decreased for at least $1 \mathrm{~h}$. Right heart insufficiency might occur and the reduction of venous return may have influenced the decreased sBP in mice.

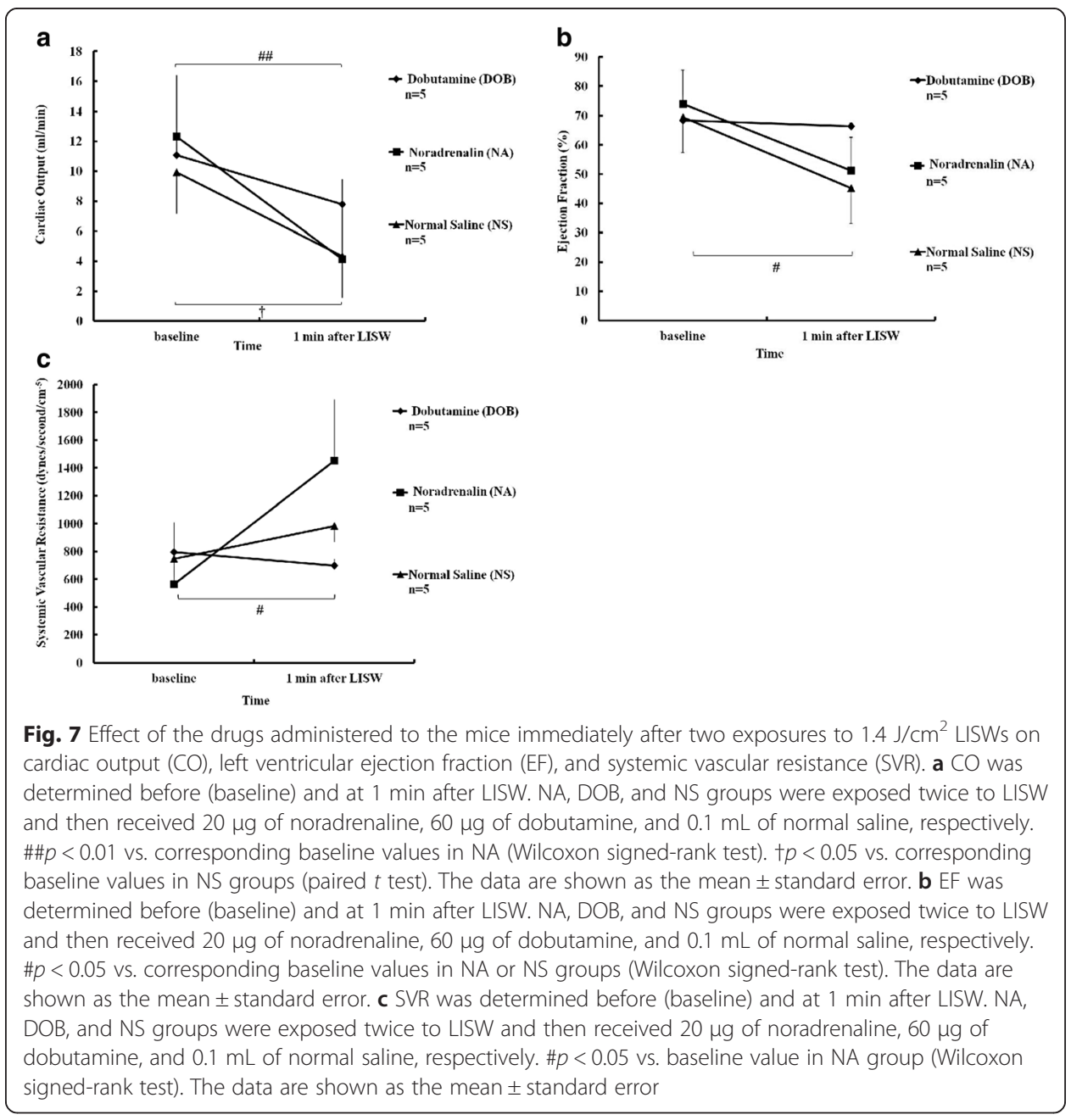


Clinically, no treatment has been established for BLI during the initial phase, such as that observed in the prehospital or battlefield setting. If the immediate administration of catecholamines is effective for victims of severe BLI during the initial phase, then the intra-muscular injection of adrenaline might be a practical treatment, as it is already easily, safely, and effectively administered to anaphylactic patients in prehospital settings [30]. The present findings suggest that the administration of $\alpha 1$-adrenergic receptor agonists may be an effective and rational initial treatment for severe BLI.

\section{Limitations}

We applied LISW twice to mice in order to create bilateral BLI, whereas most victims of explosives are exposed to only one blast wave. This experimental model might therefore differ from real situations to some extent. However, we believe that the difference is permissible because all mice exposed to LISW developed the same BLI triad of hypotension, bradycardia, and hypoxemia.

Although bradycardia may have affected the survival rate to some extent, we did not evaluate the effect of atropine because atropine administration did not result in any significant increases in HR in the C57BL/6 Sham group. Therefore, we evaluated only the effects of noradrenaline and dobutamine.

In addition, another major limitation of this study was the timing of intervention. It is unlikely that an individual with BLI will receive noradrenalin within several minutes after injury. If noradrenalin was not administered immediately after LISW, nine of ten mice died within 15 min after LISW exposure in our model. Thus, a rapid injection of noradrenalin is necessary for lifesaving according to our experiments. We will conduct further studies to develop a rapid injection system of noradrenalin for use after an actual explosion.

\section{Conclusions}

The main cause of immediate death from BLI may be hypotension due to the absence of peripheral vasoconstriction. Therefore, the immediate administration of $\alpha 1$-adrenergic receptor agonists, such as noradrenaline, might serve as an effective initial treatment for severe BLI.

\section{Abbreviations}

BLI: blast lung injury; CO: cardiac output; DOB: dobutamine; EF: ejection fraction; HR: heart rate; LISW: laser-induced shock wave; NA: noradrenalin; NS: normal saline; sBP: systolic blood pressure; $\mathrm{SpO}_{2}$ : peripheral oxyhemoglobin saturation; SVR: systemic vascular resistance.

Competing interests

The authors declare that they have no competing interests.

\section{Authors' contributions}

$\mathrm{HM}$ is the primary investigator of this study and was thus responsible for all of the study processes. DS contributed to the study design, statistical analysis, data interpretation, and writing of the manuscript. $\mathrm{KH}$ contributed to the study design, animal experiments, data interpretation, data collection, and writing of the manuscript. MN contributed to the animal experiments, data collection, and creation of the figures. SS contributed to the data interpretation and creation of the figures. MK and HM contributed to the study design. YS contributed to the animal experiments. NH contributed to writing the manuscript. TS contributed to the study design and writing the manuscript. All authors read and approved the final manuscript. 


\section{Author details}

'Department of Traumatology and Critical Care Medicine, National Defense Medical College Hospital, 3-2 Namiki, Tokorozawa 359-8513, Japan. 'Division of Traumatology, Research Institute, National Defense Medical College, 3-2 Namiki, Tokorozawa 359-8513, Japan. ${ }^{3}$ Division of Physiology, National Defense Medical College, 3-2 Namiki,

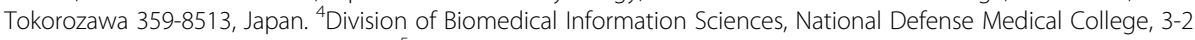
Namiki, Tokorozawa 359-8513, Japan. ${ }^{5}$ Department of Immunology and Microbiology, National Defense Medical College, 3-2 Namiki, Tokorozawa 359-8513, Japan. ${ }^{6}$ Department of Anesthesiology, National Defense Medical College,

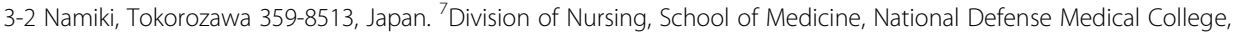
3-2 Namiki, Tokorozawa 359-8513, Japan.

Received: 6 August 2015 Accepted: 6 December 2015

Published online: 10 December 2015

\section{References}

1. Katz E, Ofek B, Adler J, Abramowitz HB, Krausz MM (1989) Primary blast injury after a bomb explosion in a civilian bus. Ann Surg 209:484-488

2. Mayorga MA (1997) The pathology of primary blast overpressure injury. Toxicology 121:17-28

3. Singer P, Cohen JD, Stein M (2005) Conventional terrorism and critical care. Crit Care Med 33:S61-S65

4. Cernak I, Savic J, Ignjatovic D, Jevtic M (1999) Blast injury from explosive munitions. J Trauma 47:96-103, discussion 103-104

5. Singleton JA, Gibb IE, Bull AM, Mahoney PF, Clasper JC (2013) Primary blast lung injury prevalence and fatal injuries from explosions: insights from postmortem computed tomographic analysis of 121 improvised explosive device fatalities. J Trauma Acute Care Surg 75:S269-S274

6. Horrocks CL (2001) Blast injuries: biophysics, pathophysiology and management principles. J R Army Med Corps 147:28-40

7. Mellor SG (1992) The relationship of blast loading to death and injury from explosion. World J Surg 16:893-898

8. Avidan V, Hersch M, Armon Y, Spira R, Aharoni D et al (2005) Blast lung injury: clinical manifestations, treatment, and outcome. Am J Surg 190:927-931

9. Pizov R, Oppenheim-Eden A, Matot I, Weiss YG, Eidelman LA et al (1999) Blast lung injury from an explosion on a civilian bus. Chest 115:165-172

10. Gutierrez de Ceballos JP, Turegano Fuentes F, Perez Diaz D, Sanz Sanchez M, Martin Llorente C et al (2005) Casualties treated at the closest hospital in the Madrid, March 11, terrorist bombings. Crit Care Med 33:S107-S112

11. Guy RJ, Kirkman E, Watkins PE, Cooper GJ (1998) Physiologic responses to primary blast. J Trauma 45:983-987

12. Jaffin JH, McKinney L, Kinney RC, Cunningham JA, Moritz DM et al (1987) A laboratory model for studying blast overpressure injury. J Trauma 27:349-356

13. Irwin RJ, Lerner MR, Bealer JF, Brackett DJ, Tuggle DW (1997) Cardiopulmonary physiology of primary blast injury. J Trauma 43:650-655

14. Ohnishi M, Kirkman E, Guy RJ, Watkins PE (2001) Reflex nature of the cardiorespiratory response to primary thoracic blast injury in the anaesthetised rat. Exp Physiol 86:357-364

15. Dodd KT, Mundie TG, Lagutchik MS, Morris JR (1997) Cardiopulmonary effects of high-impulse noise exposure. J Trauma 43:656-666

16. Irwin RJ, Lerner MR, Bealer JF, Mantor PC, Brackett DJ et al (1999) Shock after blast wave injury is caused by a vagally mediated reflex. J Trauma 47:105-110

17. Harban FMJKE, Kenward CE, Watkins PE (2001) Primary thoracic blast injury causes acute reduction in cardiac function in the anesthetized pig. J Physiol-London 533:81

18. Satoh Y, Sato S, Saitoh D, Tokuno S, Hatano B et al (2010) Pulmonary blast injury in mice: a novel model for studying blast injury in the laboratory using laser-induced stress waves. Lasers Surg Med 42:313-318

19. Sato S, Kawauchi S, Okuda W, Nishidate I, Nawashiro H et al (2014) Real-time optical diagnosis of the rat brain exposed to a laser-induced shock wave: observation of spreading depolarization, vasoconstriction and hypoxemia-oligemia. PLoS One 9:e82891

20. Frykberg ER, Tepas JJ 3rd, Alexander RH (1989) The 1983 Beirut Airport terrorist bombing. Injury patterns and implications for disaster management. Am Surg 55:134-141

21. Phillips YY (1986) Primary blast injuries. Ann Emerg Med 15:1446-1450

22. Cooper GJ (1996) Protection of the lung from blast overpressure by thoracic stress wave decouplers. J Trauma 40: S105-S110

23. Leibovici D, Gofrit ON, Stein M, Shapira SC, Noga Y et al (1996) Blast injuries: bus versus open-air bombings-a comparative study of injuries in survivors of open-air versus confined-space explosions. J Trauma 41:1030-1035

24. Frykberg ER, Tepas JJ 3rd (1988) Terrorist bombings. Lessons learned from Belfast to Beirut. Ann Surg 208:569-576

25. Tsokos M, Paulsen F, Petri S, Madea B, Puschel K et al (2003) Histologic, immunohistochemical, and ultrastructural findings in human blast lung injury. Am J Respir Crit Care Med 168:549-555

26. Daly MD, Kirkman E (1988) Cardiovascular responses to stimulation of pulmonary C fibres in the cat: their modulation by changes in respiration. J Physiol 402:43-63

27. Darley MDKE (1987) The cardiac and hindlimb vascular-responses to excitation of pulmonary C-fibers, and their modification by changes in respiration in the cat. J Physiol-London 384:52

28. Zunic G, Pavlovic R, Malicevic Z, Savic V, Cernak I (2000) Pulmonary blast injury increases nitric oxide production, disturbs arginine metabolism, and alters the plasma free amino acid pool in rabbits during the early posttraumatic period. Nitric Oxide 4:123-128

29. Zunic G, Romic P, Vueljic M, Jovanikic O (2005) Very early increase in nitric oxide formation and oxidative cell damage associated with the reduction of tissue oxygenation is a trait of blast casualties. Vojnosanit Pregl 62:273-280

30. David M JD, Leon C, Pascal C, Kin-Lai, Norda R, Adam S (2010) Circulation 122: S936. 